\title{
Great Vessels Abnormality
}

National Cancer Institute

\section{Source}

National Cancer Institute. Great Vessels Abnormality. NCI Thesaurus. Code C99137.

A cong enital vascular abnormality that affects the great vessels and/or aortic arch.

Representative examples include double aortic arch, aortic coarctation, and absence of a pulmonary artery. 